https://helda.helsinki.fi

\title{
Acute hormonal findings after aneurysmal subarachnoid hemorrhage - report from a single center
}

\section{Takala, Riikka S. K.}

2017

Takala , R S K, Kiviranta , R, Olkkola , K T, Vahlberg , T, Laukka , D , Kotkansalo , A, Rahi , M , Sankinen , M , Posti , J , Katila , A \& Rinne , J 2017 , ' Acute hormonal findings after aneurysmal subarachnoid hemorrhage - report from a single center ' , Endocrine Research, vol. 42 , no. 2 , pp. 125-131 . https://doi.org/10.1080/07435800.2016.1242603

http://hdl.handle.net/10138/311542

https://doi.org/10.1080/07435800.2016.1242603

acceptedVersion

Downloaded from Helda, University of Helsinki institutional repository.

This is an electronic reprint of the original article.

This reprint may differ from the original in pagination and typographic detail.

Please cite the original version. 


\section{ACUTE HORMONAL FINDINGS AFTER ANEURYSMAL SUBARACHNOID HEMORRHAGE - REPORT FROM A SINGLE CENTER}

Riikka SK Takala MD PhD ${ }^{1}$, Riku Kiviranta MD PhD ${ }^{2,3}$, Klaus T Olkkola MD PhD ${ }^{4}$, Tero Vahlberg MSc ${ }^{5}$, Dan Laukka MD ${ }^{6}$, Anna Kotkansalo MD ${ }^{6}$, Melissa Rahi MD PhD ${ }^{6}$, Matti Sankinen MD ${ }^{6}$, Jussi Posti MD PhD ${ }^{6,7}$, Ari Katila MD ${ }^{1}$, Jaakko Rinne $\mathrm{MD} \mathrm{PhD}^{6}$

1 Perioperative Services, Intensive Care Medicine and Pain Management Turku University Hospital and University of Turku, Turku, Finland

2 Division of Internal Medicine, Department of Endocrinology, Turku University Hospital, Turku, Finland

3 Departments of Medicine and Medical Biochemistry and Genetics, University of Turku, Turku, Finland

4 Department of Anaesthesiology and Intensive Care Medicine, University of Helsinki and Helsinki University Hospital, Helsinki, Finland

5 Department of Clinical Medicine, Biostatistics, University of Turku, and Turku University Hospital, Turku, Finland

6 Division of Clinical Neurosciences, Department of Neurosurgery, Turku University Hospital and University of Turku, Turku, Finland

7 Division of Clinical Neurosciences, Department of Rehabilitation and Brain

Trauma, Turku University Hospital and University of Turku and University of Turku, Turku, Finland

These results have been partly presented in SSAI2013 congress in August 2013.

Corresponding author:

Riikka Takala, MD PhD

Perioperative Services, Intensive Care Medicine and Pain Management

Turku University Hospital and University of Turku

TTOTEK, TG4

Hämeentie 11

20520 Turku

Finland

riikka.takala@gmail.com

Fax: +3582313960

Tel: +358405130441

Key words: Hypocortisolism, Pituitary function, Prolactin, Subarachnoid hemorrhage 


\section{ABSTRACT}

Purpose: The aim was to assess anterior pituitary hormone levels during the acute phase of aneurysmal subarachnoid hemorrhage (aSAH) and analyze the possible association with the clinical condition and outcome.

Material and Methods: Forty patients with aSAH whose aneurysm was secured by endovascular coiling were enrolled. Basal secretions of cortisol,, testosterone, luteinising hormone, prolactin and sex hormone binding globulin levels were measured up to 14 days after the incident.

Results: Main finding was that hypocortisolism was rare whereas testosterone deficiency was common in male patients. Furthermore, various other hormone deviations were frequent and there was wide inter-individual variability. We found no association between delayed cerebral ischemia, outcome of the patients or aneurysm location and hormone abnormalities, while both Hunt \& Hess and Fisher grade were associated with low prolactin levels. Hunt \& Hess 5 was associated with low prolactin concentration when compared to grades $1(\mathrm{OR}=4.81,95 \% \mathrm{CI} 1.15-20.14, \mathrm{p}=0.03), 3$ $(\mathrm{OR} 7.73,95 \% \mathrm{CI} 1.33-45.01, \mathrm{p}=0.02)$ and $4(\mathrm{OR}=6.8695 \% \mathrm{CI} 1.28-26.83, \mathrm{p}=0.02)$. Fisher grade 4 was associated with low prolactin concentration when compared to grades 3 (OR 3.37, 95\% CI 1.06-10.73, p=0.03) and 2 (OR 9.71, 95\% CI 1.22-77.10, $\mathrm{p}=0.04)$.

Conclusion: Deviations from normal and huge inter-individual differences are common in hormone levels during acute phase of aSAH. Routine assessment of anterior pituitary function in the acute phase of aSAH is not warranted. During the follow up in the outpatient clinic, hormone concentrations were not measured, which would have brought more long-term perspective into our findings. 


\section{INTRODUCTION}

Previous studies have indicated that approximately half of the patients with aneurysmal subarachnoid hemorrhage (aSAH) have low levels of anterior pituitary hormones and an anterior pituitary dysfunction $(1,2)$. In the chronic phase corticotropin and growth hormone deficiencies are most prevalent whereas sex hormone deficiencies are more infrequent $(3,4)$. These deficiencies may contribute to morbidity and poor cognitive performance after aSAH $(4,5)$. The etiology of hormone deficiencies is still unknown, albeit ischemia and brain odema have been postulated to diminish vulnerable blood supply to hypothalamus and pituitary gland, leading to their functional impairment (6).

Few previous studies have evaluated anterior pituitary hormone levels during the acute phase of aSAH. These studies have demonstrated that hypocortisolism is rare whereas low concentrations of thyroid hormone, growth hormone and gonadotropins are more common (7-12)

Our aim was to assess anterior pituitary hormone levels during the acute phase of aSAH. We measured cortisol, testosterone, luteinizing hormone (LH), prolactin (PRL) and sex hormone binding globulin (SHBG) levels for 14 days after the haemorrhage. To our knowledge, this study provides to date the longest evaluation of hormonal changes during the acute phase. In addition, we were interested on the possible association between the hormone levels and patient outcome. 


\section{MATERIAL AND METHODS}

Forty patients with aSAH and whose aneurysm was secured by endovascular coiling were enrolled into the study. The study was approved by the Ethics Committee of the Hospital District of Southwest Finland (approval number: 56/180/2009). Patients or their next of kin were given both written and oral information about the study and written informed consent was obtained. Patients who had previous hormone deficiencies, were on corticosteroid treatment or were moribund (brain death) were excluded from the study. Patients who were treated by surgical clipping were also excluded as they were given intravenous betamethason before and after craniotomy.

The amount of blood in computed tomography scans were estimated using Fisher scale (13), where $1=$ no blood detected, 2 = diffuse or vertical layers $<1 \mathrm{~mm}$ thick, 3 $=$ localised clot and/or vertical layer $\geq 1 \mathrm{~mm}$ and $4=$ intracerebral or intraventricular clot with diffuse or no SAH. Clinical condition was scored using Hunt \& Hess grades (14) where 1 = asymptomatic, mild headache, slight nuchal rigidity, $2=$ moderate to severe headache, nuchal rigidity, no neurologic deficit other than cranial nerve palsy, $3=$ drowsiness/confusion, mild focal neurologic deficit, 4 = stupor, moderate-severe hemiparesis, 5 = coma, decerebrate posturing.

All aSAH patients had either intravenous or oral nimodipine. Total intravenous anesthesia including propofol, remifentanil and rocuronium were used for the coiling procedure. Hypertension and normovolemia were part of the routine treatment modalities to prevent delayed cerebral ischemia (DCI). Patients needing pharmacological treatment to achieve hypertension were given noradrenaline.

Blood samples for the determination of serum hormone concentrations were obtained between 7-8 am on the next morning after the hemorrhage (day 1), and at the same 
time on days $3,5,7,10$ and 14 . All the samples were analyzed in the laboratory of Turku University Hospital. Electrochemiluminescence immunoassay method was used to measure plasma cortisol (reference interval 150-650 nmol/l), PRL (female 102-496 mU/l and male 86-324 mU/1), LH (male 1.7-8.6 U/l and female over 50 years 7.7-59 U/l) and SHBG (female $26-119 \mathrm{nmol} / \mathrm{l}$ and male $15-48 \mathrm{nmol} / \mathrm{l})$. The testosterone/SHBG ratio was calculated in male patients (reference interval 4101400). Serum testosterone was measured by radioimmunoassay with reference interval for male $10-33 \mathrm{nmol} / \mathrm{l}$ and female $0.6-2.4 \mathrm{nmol} / \mathrm{l}$. Although the lowest plasma cortisol reference value was $150 \mathrm{nmol} / \mathrm{l}$, the current literature suggests that diagnostic criteria for hypocortisolism in critical illness is random cortisol level $<10 \mathrm{~g} / \mathrm{dl}$ (275 nmol/l) (15) and this criteria was applied.

Clinical condition was graded according to Hunt \& Hess, and Fisher grade was used to rank the amount of blood in the first CT scan. Patient outcome at 6 months was graded using Glasgow outcome scale (GOS), which was dichotomized into favourable (GOS 5 and 4) and unfavourable (GOS 3, 2 and 1). Outcome was assessed at 6 months after aSAH using Glasgow Outcome Scale (GOS) (16), where 1 = death, $2=$ persistent vegetative state, $3=$ severe disability, $4=$ moderate disability and $5=$ good recovery. Outcome was further dichotomized and GOS 4-5 was classified as favourable and GOS 1-3 as unfavourable outcome.

Statistical analysis was done with SAS System for Windows, version 9.3 (SAS Institute Inc., Cary, NC, USA). Repeated measures analysis of variance (ANOVA) with compound symmetry covariance structure was used to analyse changes in the hormone concentrations during the study period. Dunnett's method was used to compare the hormone concentrations on the follow-up days with day 1. Only cortisol levels were normally distributed. After logarithmic transformation all other variables 
were normally distributed, enabling ANOVA analysis. Logistic regression analysis was used to analyse associations between abnormally low hormone concentrations and Hunt \& Hess, Fisher grading, aneurysm location and DCI. Generalized estimating equations (GEE) with exchangeable correlation structure were used in logistic models to account for the correlation between repeated measurements. Demographic and cortisol data is presented as means and standard deviations (SD) and other data as medians interquartile ranges (IQR). P-value $<0.05$ was considered statistically significant. 


\section{RESULTS:}

The demographic data of our patients with the Fisher and Hunt \& Hess grades are summarized in Table 1. Altogether, 26 women and 14 men were recruited. The mean age was $58.1(10.2)$ years. In 32 patients the aneurysm was located in the anterior and in 8 patients in the posterior circulation. GOS at six months after the incident was favourable in 22 and unfavourable in 14 patients. Outcome data was missing for four patients.

There was only one female patient, who had completely normal hormonal findings during the entire study period. All other 39 patients had at least one abnormal laboratory finding. There was no association between abnormal hormone levels and dichotomized outcome (favourable vs. unfavourable) of the patients or between aneurysm location.

Nineteen patients developed DCI. In eight patients the diagnosis was based on clinical deterioration, in two patients the diagnosis was confirmed during conventional angiography, in eight patients based on a new infarct seen on computed tomography and in one patient the diagnosis was made using transcranial Doppler. DCI appeared 5.5 (3.0) days after aSAH. DCI was not associated with hormone abnormalities (data not shown).

\section{Serum cortisol}

Most of the patients had high serum cortisol levels, above $650 \mathrm{nmol} / \mathrm{l}$, during the first five days. On the first morning after the ictus, 20/37 (the first morning sample was not obtained from three patients) patients had cortisol levels above $650 \mathrm{nmol} / \mathrm{l}$. Only 4/37 patients had cortisol levels lower than $275 \mathrm{nmol} / \mathrm{l}$. However, cortisol replacement 
therapy was given to two patients whose cortisol level was below $150 \mathrm{nmmol} / \mathrm{l}$. The cortisol levels decreased slowly after the ictus and this decrease was statistically significant during the study period $(\mathrm{p}=0.0009)$ (Figure 1$)$. The decrease was significant on days 10 and 14 compared to day $1(\mathrm{p}=0.006$ and $\mathrm{p}=0.0003$, respectively). Mean and SD cortisol levels are presented on Table 2.

\section{Serum testosterone male}

Twelve out of 14 males had serum testosterone deficiency $(<10 \mathrm{nmol} / \mathrm{l})$ at least twice during the measurements. Four of these 12 patients showed testosterone deficiency in all seven measurements, whereas 3/12 patients had low levels in five time points and 3/12 patients in four time points. Median testosterone levels are presented on Table 2 and figure 2 displays the mean profiles for male testosterone levels. In the whole study population, the mean testosterone/SHGB ratios (reflects biologically active testosterone) were below lower limit (410) throughout the study period, Figure 2.

\section{Luteinizing hormone in female patients}

Sixteen female patients had at least one low LH concentration during the study period. One of these patients had low levels in all measurements whereas four patients had low concentrations in five measurements. Two patients had low concentrations in three, four patients had low concentrations in two and five patients had low concentrations in one measurement, respectively.

\section{Luteinizing hormone in male patients}

Two patients had low LH levels twice and five patients had a single low LH measurement. These low levels had no discernible pattern in the timing of decreased testosterone levels. Only three patients had elevated LH concentrations. 


\section{Prolactin}

There was an association between low prolactin levels and Hunt \& Hess grades as well as with Fisher grades. Hunt \& Hess grade 5 was associated with low concentration when compared to grades $1(\mathrm{OR}=4.81,95 \% \mathrm{CI} 1.15-20.14, \mathrm{p}=0.03), 3$

(OR 7.73, 95\% CI 1.33-45.01, $\mathrm{p}=0.02)$ and $4(\mathrm{OR}=6.8695 \% \mathrm{CI} 1.28-26.83, \mathrm{p}=0.02)$.

Fisher grade 4 was also associated with low prolactin concentration when compared to grades 3 (OR 3.37, 95\% CI 1.06-10.73, p=0.03) and 2 (OR 9.71, 95\% CI 1.2277.10, $\mathrm{p}=0.04)$. Median prolactin levels are shown in Table 3.

\section{Prolactin in female patients}

One patient had low prolactin levels during four measurements. One patient had low levels in three measurements and one patient in two measurements. Single low levels were observed in six patients.

High values were found four times in one patient, three times in one additional patient and twice in two patients. Interestingly, two patients had once both low and high values.

\section{Prolactin in male patients}

One male had low levels in three measurements and one patient in two measurements. Two patients had isolated low measurements. High prolactin values were seen in one patient in all six measurements and one patient had high values twice. Four patients had only one low prolactin value. 


\section{DISCUSSION}

Our main finding was that hypocortisolism was rare while slightly elevated cortisol levels were observed frequently in our patients. Moreover testosterone deficiency in male patients was very common during the acute phase of aSAH. Mild fluctuations in the other anterior pituitary hormones were also observed frequently. These fluctuations did not show any distinct temporal pattern after the onset of aSAH but could at least in part represent the pulsatile secretion of many of the hormones. On average, we observed no association between the outcome of the patients and hormone levels. However, both Hunt \& Hess and Fisher gradings were associated with low prolactin levels. Furthermore, there was no association between aneurysm location and hormone levels, which is in accordance with others (10). Our results regarding the outcome are not in line with previous studies, which have observed correlations with worse clinical status and outcome with other hormonal abnormalities(17-19). Dopamine (20,21) and etomidate (22) are known to have effect on hormone secretion but the observed hormone abnormalities in our study were not attributed to them as dopamine or etomidate were not used in any of our patients.

\section{Cortisol}

High cortisol levels in our patients are in accordance with other studies $(7,9,11)$. The early response is likely due to stress-induced upregulation of CRH and ACTH but the later elevation could be caused by decreased degradation of cortisol, as suggested in a mixed population of critically ill patients (23-25). Unfortunately, we could not confirm this by ACTH measurements in this study. $5 \%$ of our patients had low cortisol level and despite being rare, adrenal insufficiency should be suspected if the patient is hemodynamically unstable and is in need of high doses of vasopressors. 
Although adrenal insufficiency is uncommon during the acute phase, there is some indication that adrenocortical insufficiency may be present after three months to one year after the haemorrhage $(4,26)$.

\section{Luteinizing hormone}

Most women in our study were postmenopausal as the mean age of women was 59. However, due to the bleeding, patients were confused and disorientated, had loss of short term memory or consciousness, it was difficult and impossible to obtain reliable information regarding the timing of their last periods or ceased periods. In addition, due to afore mentioned reasons and lack of previous medical treatment in our hospital, we did not have available data regarding possible hormone replacement therapy or contraception.

\section{Prolactin}

Altogether 16 (40\%) patients had high prolactin levels. Critical illness and stress are known to increase prolactin levels, most likely due to increased adrenergic activity of the hypothalamus (27). In addition, it has been suggested that increased prolactin levels could be associated with epileptic seizures $(28,29)$. However, none of these 16 patients had seizures nor were they on dopamine antagonist medication, which could also explain the increased secretion. It has been reported previously that during acute phase of aSAH, $31 \%$ of patients, have increased prolactin levels (17). However, it is unclear whether these patients showed epileptic seizures or not as this was not reported. Perhaps generalised stress reaction and possible oedema compressing the hypothalamus and/or pituitary stalk leads to increased prolactin secretion. Another possible explanation for increased prolactin levels in our patients is the use of opioids (30) where as antipsychotics or antidepressants (30) were not used in our patients. 
Real prolactin deficiency is uncommon and is usually related to other pituitary hormone deficiencies (31). 13 (32.5\%) patients had low prolactin concentrations, which however were not related to other hormone concentrations. Although the most severe form of aSAH presentation correlated with low prolactin concentrations, the meaning or cause of the low prolactin concentration in our study remains unclear.

\section{Testosterone}

Low testosterone concentrations were observed in most of the male patients and biologically active testosterone (testosterone/SHBG ratio) was also low. Hypogonadotropic hypogonadism is unlikely and secondary hypogonadism more likely as low LH concentrations were infrequent (31). Similar findings have been observed also previously and these changes seem to be transient (17), probably resulting from an illness induced stress reaction and direct suppression of testosterone production by stress-induced cytokines (32).

\section{Limitations}

Our study has some limitations. First of all, we collected samples only from 40 patients and our results apply only to aSAH patients whose aneurysms were coiled. On the other hand this rules out the possible effect of craniotomy and surgical stress on our findings. Other studies have included also patients who had undergone craniotomy and clipping $(4,12,17,18)$ and it is possible that surgery may have affected hormone profiles (33) in these studies. In future studies both types of treatment modalities should be taken into account during the analysis and interpretation of the results. Secondly, we measured only basal hormone secretion whereas additional stimulated hormone concentrations could have given further insight into pituitary function in these patients. Lastly, we did not measure hormone concentrations during 
the follow up in the outpatient clinic, which would have brought more long-term perspective into our findings. This would have revealed those patients who would have developed hormonal deficiencies at later stage, and their possible correlation with the long-term co-morbidities of aSAH such as neuropsychological deficiencies or depression. On the other hand, some studies have demonstrated that acute phase abnormalities do not predict the development of pituitary dysfunctions at the later stage $(1,34)$. Many of the aSAH patients in our study came from other hospital districts without neurosurgical facilities and their follow up is organised locally in their own hospital district by neurologists.

Anterior pituitary hormone concentrations during the acute phase of aSAH have been evaluated also previously. However, in these previous studies the sampling time has been shorter and/or only one sample obtained, varying from a single 1st day sample up to 15 days $(12,17-19)$. We obtained samples at six time points and measured hormone concentrations up to 14 days post ictus. Based on our results, apart from ACTH-cortisol axis, it seems unnecessary to measure anterior pituitary function routinely during the onset of aSAH as the various hormone concentrations vary even daily within the subjects. However, their assessment at later stage during the longterm follow-up should be considered in those patients who have not recovered as expected. 


\section{FUNDING}

This study was funded with EVO 13693 (Klaus T. Olkkola) grant from Hospital

District of South-West Finland

\section{DECLARATION OF INTEREST}

Declaration of interest: The authors report no conflicts of interest. The authors alone are responsible for the content and writing of the paper. 


\section{REFERENCES}

1. Schneider HJ, Kreitschmann-Andermahr I, Ghigo E, Stalla GK, Agha A. Hypothalamopituitary dysfunction following traumatic brain injury and aneurysmal subarachnoid hemorrhage. JAMA 2007;298:1429-1438.

2. Kopczak A, Kilimann I, Rosen von F et al. Screening for hypopituitarism in 509 patients with traumatic brain injury or subarachnoid hemorrhage. Journal of Neurotrauma 2014;31:99-107.

3. Dimopoulou I, Kouyialis AT, Tzanella M et al. High Incidence of Neuroendocrine Dysfunction in Long-Term Survivors of Aneurysmal Subarachnoid Hemorrhage. Stroke 2004;35:2884-2889.

4. Kreitschmann-Andermahr I. Prevalence of Pituitary Deficiency in Patients after Aneurysmal Subarachnoid Hemorrhage. Journal of Clinical Endocrinology \& Metabolism 2004;89:4986-4992.

5. The Participants in the International Multi-disciplinary Consensus Conference on the Critical Care Management of Subarachnoid Hemorrhage, Vespa P. Endocrine Function Following Acute SAH. Neurocrit Care 2011;15:361-364.

6. Vespa PM. Hormonal dysfunction in neurocritical patients. Current Opinion in Critical Care 2013;19:107-112.

7. Bendel S, Koivisto T, Ruokonen E et al. Pituitary-adrenal function in patients with acute subarachnoid haemorrhage: a prospective cohort study. Critical Care 2008;12:R126.

8. Mangieri P, Suzuki K, Ferreira M, Domingues L, Casulari LA. Evaluation of pituitary and thyroid hormones in patients with subarachnoid hemorrhage due to ruptured intracranial aneurysm. Arq Neuropsiquiatr 2003;61:14-19.

9. Poll E-M, Boström A, Bürgel U et al. Cortisol dynamics in the acute phase of aneurysmal subarachnoid hemorrhage: associations with disease severity and outcome. Journal of Neurotrauma 2010;27:189-195.

10. Parenti G, Cecchi PC, Ragghianti B et al. Evaluation of the anterior pituitary function in the acute phase after spontaneous subarachnoid hemorrhage. Journal of endocrinological investigation 2011;34:361.

11. Zetterling M, Engström BE, Hallberg L et al. Cortisol and adrenocorticotropic hormone dynamics in the acute phase of subarachnoid haemorrhage. $\mathrm{Br} \mathrm{J}$ Neurosurg 2011;25:684-692.

12. Tanriverdi F, Dagli AT, Karaca $Z$ et al. High risk of pituitary dysfunction due to aneurysmal subarachnoid haemorrhage: a prospective investigation of anterior pituitary function in the acute phase and 12 months after the event. Clinical Endocrinology 2007;67:931-937.

13. Fisher CM, Kistler JP, Davis JM. Relation of cerebral vasospasm to subarachnoid hemorrhage visualized by computerized tomographic scanning. 
Neurosurgery 1980;6:1-9.

14. Hunt WE, Hess RM. Surgical risk as related to time of intervention in the repair of intracranial aneurysms. Journal of Neurosurgery 1968;28:14-20.

15. Marik PE, Pastores SM, Annane D et al. Recommendations for the diagnosis and management of corticosteroid insufficiency in critically ill adult patients: Consensus statements from an international task force by the American College of Critical Care Medicine. Critical Care Medicine 2008;36:1937-1949.

16. Jennett B, Teasdale G, Braakman R, Minderhoud J, Knill-Jones R. Predicting outcome in individual patients after severe head injury. Lancet 1976;1:10311034.

17. Klose M, Brennum J, Poulsgaard L, Kosteljanetz M, Wagner A, FeldtRasmussen U. Hypopituitarism is uncommon after aneurysmal subarachnoid haemorrhage. Clinical Endocrinology 2010;73:95-101.

18. Zetterling M, Engström BE, Arnardottir S, Ronne-Engström E. Somatotropic and thyroid hormones in the acute phase of subarachnoid haemorrhage. Acta Neurochir (Wien) 2013;155:2053-2062.

19. Pereira JL, Albuquerque LA, Dellaretti M et al. Pituitary deficiency after aneurysmal subarachnoid hemorrhage. Clinics 2013;68:745-749.

20. Schilling T, Gründling M, Strang CM, Möritz K-U, Siegmund W, Hachenberg T. Effects of dopexamine, dobutamine or dopamine on prolactin and thyreotropin serum concentrations in high-risk surgical patients. Intensive Care Med 2004;30:1127-1133.

21. Van den Berghe G, de Zegher F. Anterior pituitary function during critical illness and dopamine treatment. Critical Care Medicine 1996;24:1580-1590. d

22. Albert SG, Ariyan S, Rather A. The effect of etomidate on adrenal function in critical illness: a systematic review. Intensive Care Med 2011;37:901-910.

23. Boonen E, Vervenne H, Meersseman P et al. Reduced Cortisol Metabolism during Critical Illness. N Engl J Med 2013;368:1477-1488.

24. Peeters B, Boonen E, Langouche L, Van den Berghe G. The HPA axis response to critical illness: New study results with diagnostic and therapeutic implications. Mol. Cell. Endocrinol. 2015;408:235-240.

25. Boonen E, Langouche L, Janssens T et al. Impact of Duration of Critical Illness on the Adrenal Glands of Human Intensive Care Patients. Journal of Clinical Endocrinology \& Metabolism 2014;99:4214-4222.

26. Kreitschmann-Andermahr I, Poll EM, Reineke A et al. Diagnosing neuroendocrine dysfunction in patients after aneurysmal subarachnoid hemorrhage in clinical practice - does basal hormone screening make sense? Exp. Clin. Endocrinol. Diabetes 2008;116:276-281. 
27. Langouche L, Van den Berghe G. Hypothalamic-pituitary hormones during critical illness: a dynamic neuroendocrine response. 1st ed. Elsevier B.V.; 2014:115-126.

28. Chen DK, So YT, Fisher RS. Use of serum prolactin in diagnosing epileptic seizures: Report of the Therapeutics and Technology Assessment Subcommittee of the American Academy of Neurology. Neurology 2005;65:668-675.

29. Vukmir RB. Does serum prolactin indicate the presence of seizure in the emergency department patient? J. Neurol. 2004;251:736-739.

30. Molitch ME. Drugs and prolactin. Pituitary 2008;11:209-218.

31. Ascoli P, Cavagnini F. Hypopituitarism. Pituitary 2006;9:335-342.

32. Van den Berghe G, de Zegher F, Bouillon R. Clinical review 95: Acute and prolonged critical illness as different neuroendocrine paradigms. Journal of Clinical Endocrinology \& Metabolism 1998;83:1827-1834.

33. Desborough JP. The stress response to trauma and surgery. British Journal of Anaesthesia 2000;85:109-117.

34. Alavi SA, Tan CL, Menon DK, Simpson HL, Hutchinson PJ. Incidence of pituitary dysfunction following traumatic brain injury: A prospective study from a regional neurosurgical centre. Br J Neurosurg 2016;30:302-306. 
Table 1. Demographics of the data

Table 1. Demographics of the data

Age all, mean (SD)

$58.1(10.2)$

Age female, mean (SD)

$59.2(9.8)$

Age male, mean (SD)

$56.0(10.9)$

Smokers

$15(37.5 \%)$

Non smokers

$14(35.0 \%)$

Smoking status not known

$11(27.5 \%)$

Hypertension

$12(30 \%)$

\section{Aneurysm location:}

A. Comm. Ant.

$13(32.5 \%)$

A. Cerebri Med

$11(27.5 \%)$

A. Carotis Int

$5(12.5 \%)$

A. Basilaris

$5(12.5 \%)$

A. Pericallosa

$3(7.5 \%)$

A. Vertebralis

$2(5.0 \%)$

A. Comm. Post.

$1(2.5 \%)$

\section{Hunt \& Hess}

Grade I

$11(27.50 \%)$

Grade II

$9(22.5 \%)$

Grade III

$5(12.5 \%)$

Grade IV

$7(17.5 \%)$

Grade V

$8(20.0 \%)$

\section{Fisher grade}

Diffuse or vertical layers $<1 \mathrm{~mm}$ thick

$7(17.5 \%)$

Localised clot/vertical layer $\geq 1 \mathrm{~mm}$

$18(45.0 \%)$ 
Intracerebral or intraventricular clot with diffuse or no

SAH

\section{Glasgow Outcome Scale}

1 death

$8(22.2 \%)$

2 persistent vegetative state

$1(2.8 \%)$

3 severe disability

$5(13.9 \%)$

4 moderate disability

$7(19.4 \%)$

5 good recovery

$15(41.7 \%)$

Glasgow Outcome Scale dichotomised

1-3 unfavourable recovery

$14(38.9 \%)$

4-5 good recovery

$22(61.1 \%)$ 
Table 2. Mean and SD of cortisol and numbers of patients with $<275 \mathrm{nmol} / \mathrm{l}$ cortisol levels. Median and IQR (interquartile range) of testosterone levels. Reference values are presented in parenthesis.

\begin{tabular}{|c|c|c|c|c|c|c|}
\hline \multirow[b]{2}{*}{ DAY } & \multicolumn{2}{|c|}{$\begin{array}{c}\text { Cortisol (150-600 } \\
\mathrm{nmol} / \mathrm{l})\end{array}$} & \multicolumn{2}{|c|}{ Cortisolo $<275 \mathrm{nmol} / \mathrm{l}$} & \multicolumn{2}{|c|}{$\begin{array}{l}\text { Testosterone male }(\mathbf{1 0 - 3 3} \\
\mathrm{nmol} / \mathrm{l})\end{array}$} \\
\hline & $\mathbf{N}$ & Mean (SD) & $\mathbf{N}$ & & $\mathbf{N}$ & Median (IQR) \\
\hline 1 & 36 & $758(403)$ & 36 & 4 & 12 & $\begin{array}{c}8.15(3.65- \\
14.30)\end{array}$ \\
\hline 3 & 36 & $600(278)$ & 36 & 5 & 13 & $\begin{array}{l}4.70(2.95- \\
\quad 6.40)\end{array}$ \\
\hline 5 & 35 & $665(301)$ & 35 & 4 & 13 & $\begin{array}{l}5.00(2.70- \\
9.00)\end{array}$ \\
\hline 7 & 34 & $590(277)$ & 34 & 3 & 11 & $\begin{array}{l}4.10(2.40- \\
\quad 8.20)\end{array}$ \\
\hline 10 & 33 & $520(239)$ & 33 & 6 & 13 & $\begin{array}{l}5.10(2.85- \\
\quad 8.55)\end{array}$ \\
\hline 14 & 20 & $412(187)$ & 20 & 6 & 7 & $\begin{array}{c}6.30(3.20- \\
9.10)\end{array}$ \\
\hline
\end{tabular}


Table 3. Median and IQR (interquartile range) of prolactin levels. Reference values are presented in parenthesis.

\begin{tabular}{ccccc}
\hline \multicolumn{2}{c}{ Prolactin female $(\mathbf{1 0 2 - 4 9 6} \mathbf{~ m U} / \mathbf{l})$} & \multicolumn{2}{c}{ Prolactin male $(\mathbf{8 6 - 3 2 4} \mathbf{~ m U} / \mathbf{l})$} \\
\hline Day & $\mathbf{N}$ & Median (IQR) & $\mathbf{N}$ & Median (IQR) \\
$\mathbf{1}$ & 23 & $242(102-354)$ & 12 & $150(98-222)$ \\
$\mathbf{3}$ & 24 & $218(111-370)$ & 13 & $118(96-201)$ \\
$\mathbf{5}$ & 23 & $249(158-394)$ & 13 & $202(156-272)$ \\
$\mathbf{7}$ & 24 & $219(162-372)$ & 11 & $268(181-302)$ \\
$\mathbf{1 0}$ & 21 & $333(203-469)$ & 13 & $273(207-351)$ \\
$\mathbf{1 4}$ & 13 & $370(286-517)$ & 7 & $278(240-443)$
\end{tabular}


Figure 1. Mean (standard error) cortisol (nmol/l) levels during the study period.

Reference values are presented with dashed lines. The decrease in cortisol levels after the ictus was statistically significant $(\mathrm{p}=0.009)$. The decrease was significant on days 10 and 14 compared to day 1 ( $\mathrm{p}=0.006$ and $\mathrm{p}=0.0003$, respectively).

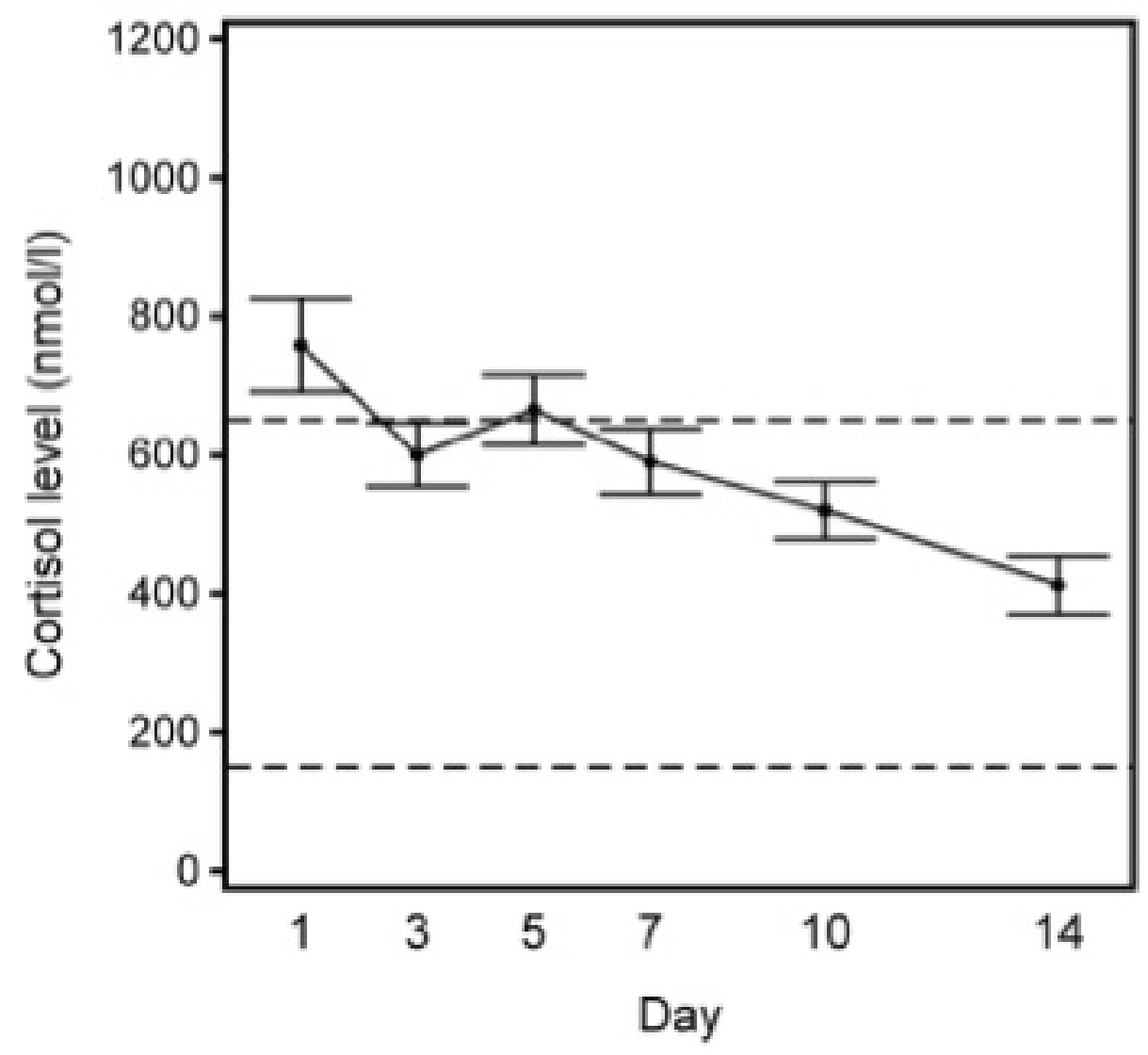


Figure 2. Mean (standard error) profiles for male testosterone levels (mmol/l) (A) and testosterone/SHBG values (B). Reference values are presented with dashed lines. The change in testosterone levels or testosterone/SHBG values was not significant ( $\mathrm{p}=$ 0.12 and $\mathrm{p}=0.20$, respectively).

A

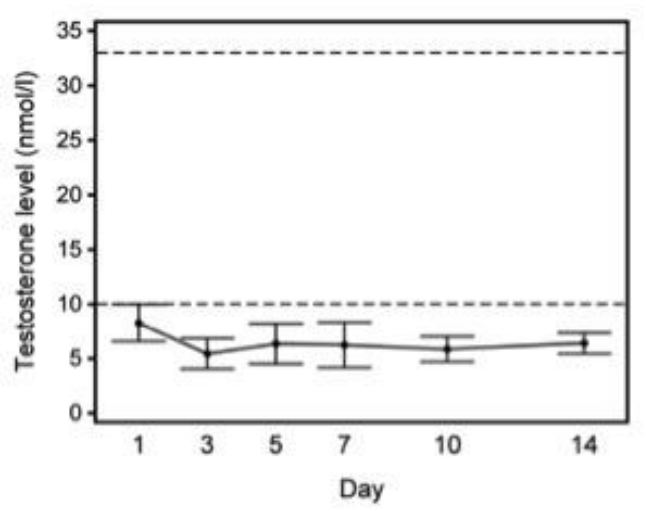

B

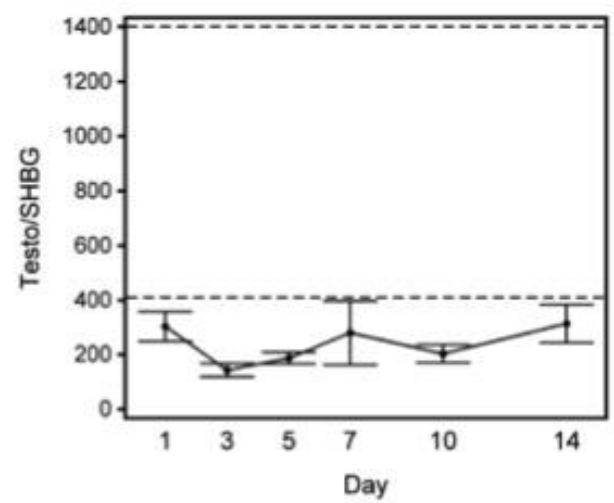


Table 1. Demographics of the data

Age all, mean (SD)

$58.1(10.2)$

Age female, mean (SD)

$59.2(9.8)$

Age male, mean (SD)

$56.0(10.9)$

Smokers

$15(37.5 \%)$

Non smokers

$14(35.0 \%)$

Smoking status not known

$11(27.5 \%)$

Hypertension

$12(30 \%)$

\section{Aneurysm location:}

A. Comm. Ant.

$13(32.5 \%)$

A. Cerebri Med

$11(27.5 \%)$

A. Carotis Int

$5(12.5 \%)$

A. Basilaris

$5(12.5 \%)$

A. Pericallosa

$3(7.5 \%)$

A. Vertebralis

$2(5.0 \%)$

A. Comm. Post.

$1(2.5 \%)$

\section{Hunt \& Hess}

Grade I

$11(27.50 \%)$

Grade II

$9(22.5 \%)$

Grade III

$5(12.5 \%)$

Grade IV

$7(17.5 \%)$

Grade V

$8(20.0 \%)$

\section{Fisher grade}

Diffuse or vertical layers $<1 \mathrm{~mm}$ thick

$7(17.5 \%)$

Localised clot/vertical layer $\geq 1 \mathrm{~mm}$

$18(45.0 \%)$

Intracerebral or intraventricular clot with diffuse or no

$15(37.5 \%)$

$\mathrm{SAH}$ 
Glasgow Outcome Scale

1 death

$8(22.2 \%)$

2 persistent vegetative state

$1(2.8 \%)$

3 severe disability

$5(13.9 \%)$

4 moderate disability

$7(19.4 \%)$

5 good recovery

$15(41.7 \%)$

Glasgow Outcome Scale dichotomised

1-3 unfavourable recovery

$14(38.9 \%)$

4-5 good recovery

$22(61.1 \%)$ 
Table 2. Mean and SD of cortisol and number of patients with $<275 \mathrm{nmol} / \mathrm{l}$ cortisol levels. Median and IQR (interquartile range) of testosterone levels. Reference values are presented in parenthesis.

\begin{tabular}{ccccccc}
\hline & Cortisol (150-600 nmol/l) & \multicolumn{2}{c}{ Cortisol < 275 nmol// } & \multicolumn{2}{c}{ Testosterone male (10-33 nmol/l) } \\
\hline DAY & $\mathbf{N}$ & Mean (SD) & $\mathbf{N}$ & $\mathbf{N}$ & Median (IQR) \\
$\mathbf{1}$ & 36 & $758(403)$ & 36 & 4 & 12 & $8.15(3.65-14.30)$ \\
$\mathbf{3}$ & 36 & $600(278)$ & 36 & 5 & 13 & $4.70(2.95-6.40)$ \\
$\mathbf{5}$ & 35 & $665(301)$ & 35 & 4 & 13 & $5.00(2.70-9.00)$ \\
$\mathbf{7}$ & 34 & $590(277)$ & 34 & 3 & 11 & $4.10(2.40-8.20)$ \\
$\mathbf{1 0}$ & 33 & $520(239)$ & 33 & 6 & 13 & $5.10(2.85-8.55)$ \\
$\mathbf{1 4}$ & 20 & $412(187)$ & 20 & 6 & 7 & $6.30(3.20-9.10)$
\end{tabular}


Table 3. Median and IQR (interquartile range) of prolactin levels. Reference values are presented in parenthesis.

\begin{tabular}{crrrr}
\hline & & Prolactin female (102-496 mU/l) & \multicolumn{2}{c}{ Prolactin male (86-324 mU/l) } \\
\hline Day & $\mathbf{N}$ & Median (IQR) & Median (IQR) \\
$\mathbf{1}$ & 23 & $242(102-354)$ & 12 & $150(98-222)$ \\
$\mathbf{3}$ & 24 & $218(111-370)$ & 13 & $118(96-201)$ \\
$\mathbf{5}$ & 23 & $249(158-394)$ & 13 & $202(156-272)$ \\
$\mathbf{7}$ & 24 & $219(162-372)$ & 11 & $268(181-302)$ \\
$\mathbf{1 0}$ & 21 & $333(203-469)$ & 13 & $273(207-351)$ \\
$\mathbf{1 4}$ & 13 & $370(286-517)$ & 7 & $278(240-443)$
\end{tabular}


Figure 1. Mean (standard error) cortisol (nmol/l) levels during the study period. Reference values are presented with dashed lines. The decrease in cortisol levels after the ictus was statistically significant $(\mathrm{p}=0.009)$. The decrease was significant on days 10 and 14 compared to day 1 ( $\mathrm{p}=0.006$ and $\mathrm{p}=0.0003$, respectively).

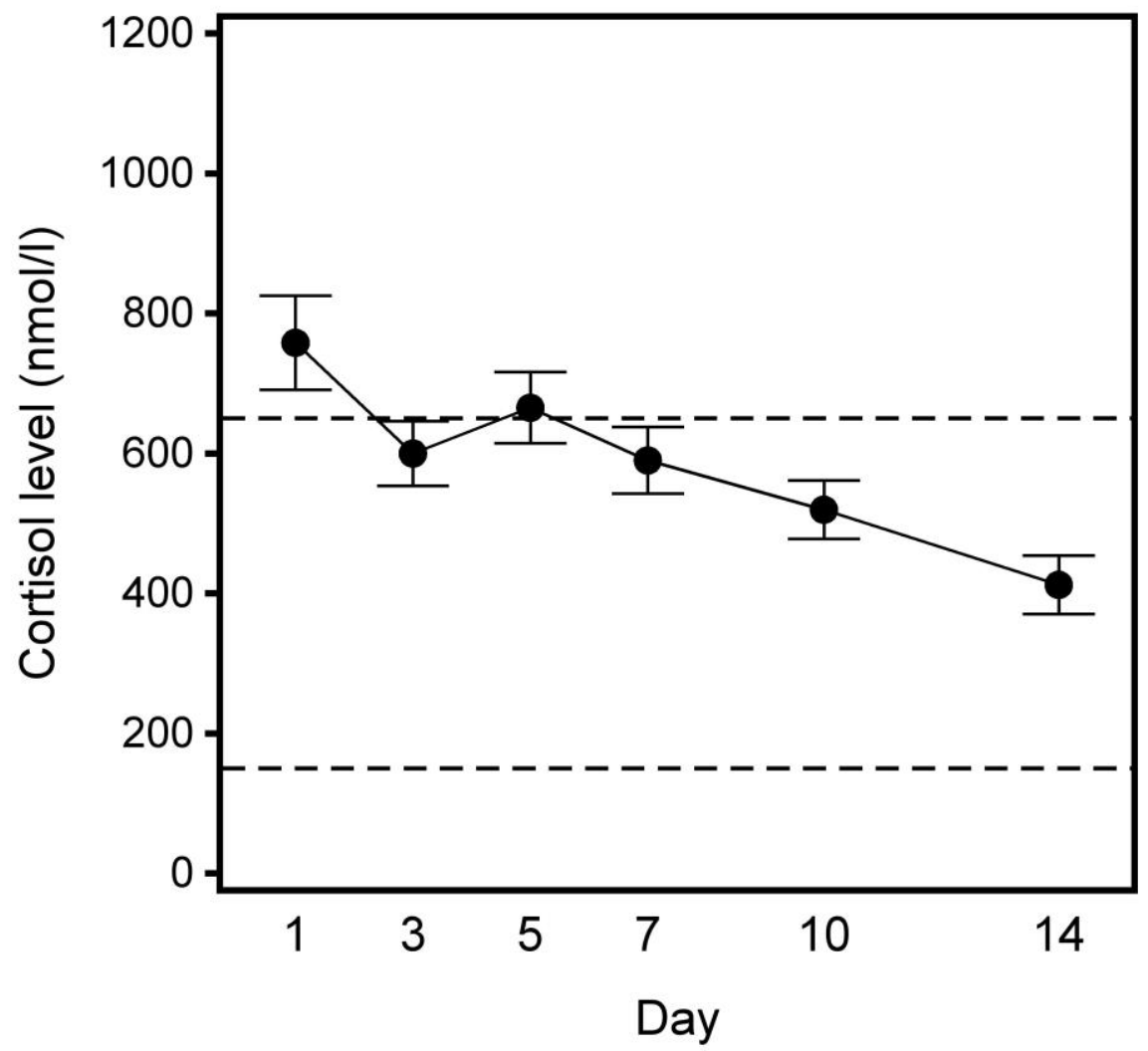


Figure 2. Mean (standard error) profiles for male testosterone levels (mmol/l) (A) and testosterone/SHBG values (B). Reference values are presented with dashed lines. The change in testosterone levels or testosterone/SHBG values was not significant ( $\mathrm{p}=0.12$ and $\mathrm{p}=0.20$, respectively).

A

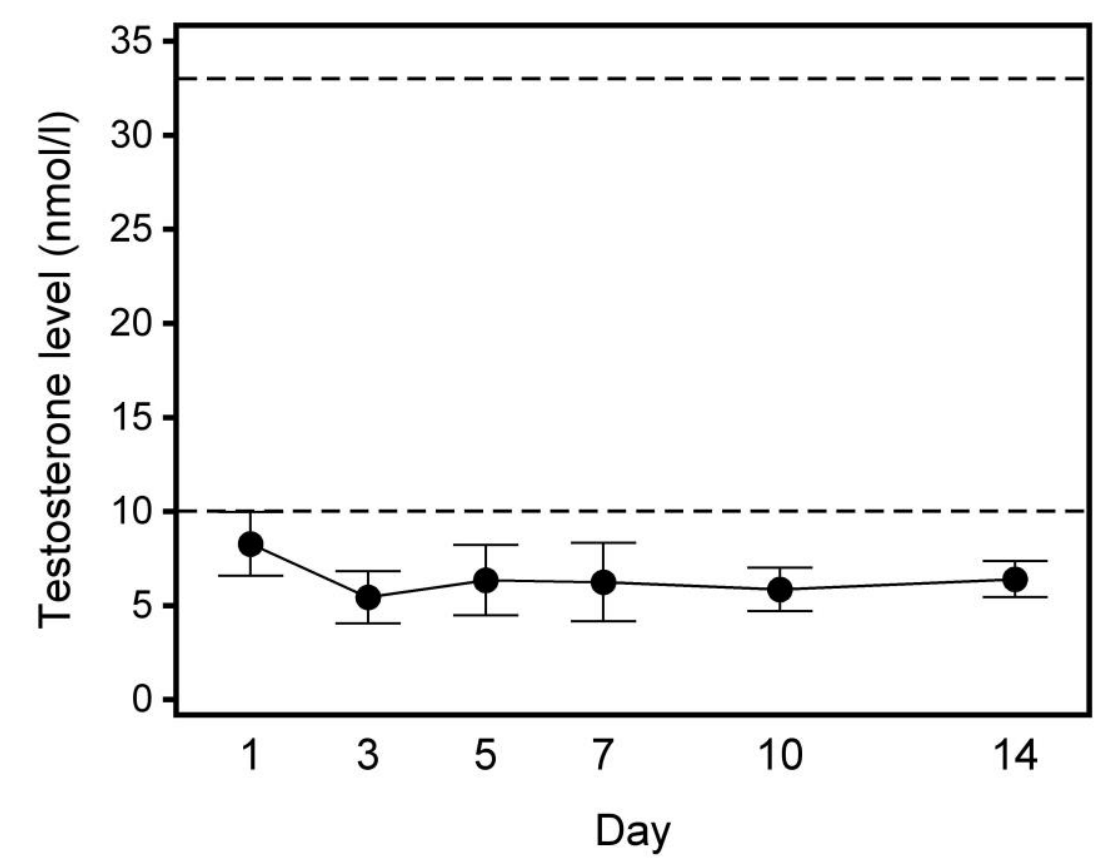

B

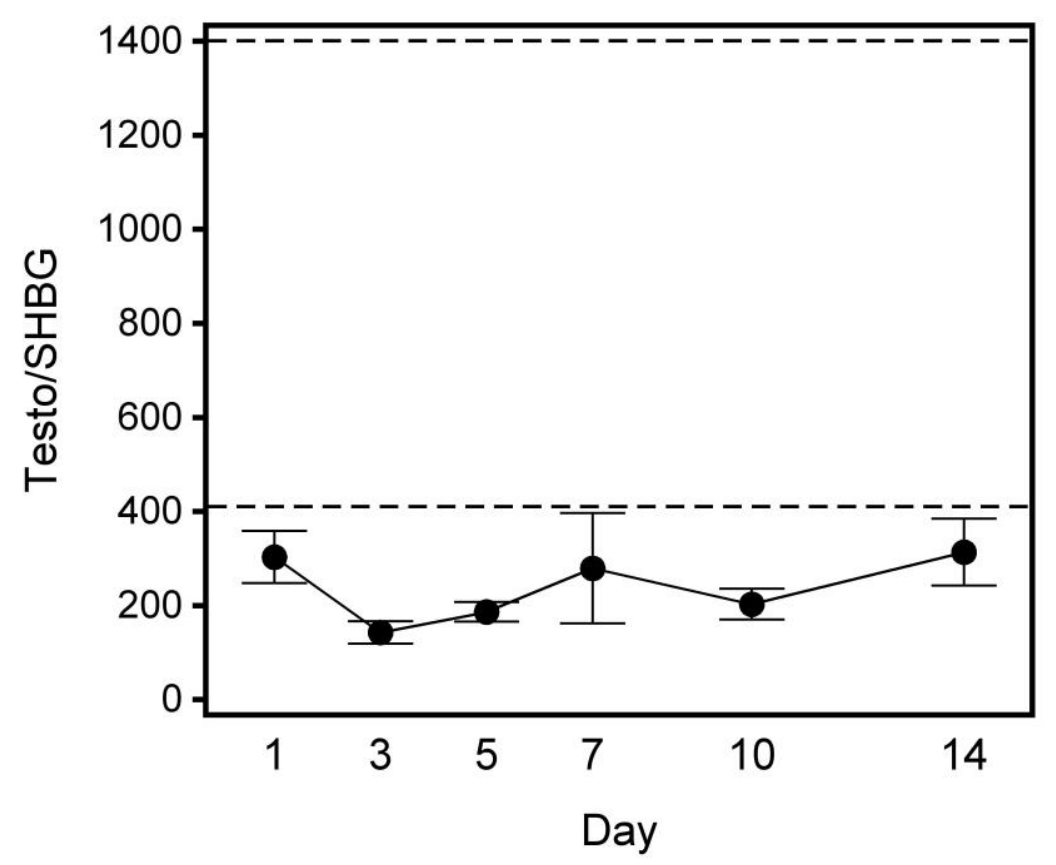

